\title{
LAY-OPEN PULMONARY ARTERIOPLASTY FOR POSTOPERATIVE HILAR PULMONARY ARTERY STENOSIS
}

Yukihiro Kaneko, MD

Hideo Okabe, MD

Nobuhiro Nagata, MD

Hiroshi Ohuchi, MD

Jotaro Kobayashi, MD

Shinya Kanemoto, MD

Kenji Itoh, MD

\begin{abstract}
Objective: Lay-open pulmonary arterioplasty, a novel surgical technique to enlarge postoperative stenosis at the hilar pulmonary artery, was evaluated. Methods: Lay-open arterioplasty, in which the enlarged hilar stenotic pulmonary artery is partially made up of previous surgical scar tissue instead of being covered by a patch, was performed on 10 patients whose ages ranged from 2.2 to 15.7 years. Surgical results were assessed by angiography. Results: All patients tolerated the procedure without bleeding or embolic complications associated with pulmonary arterioplasty. Nine patients underwent concomitant procedures including total repair $(n=5)$, central interposing shunt $(n=3)$, and right ventricular outflow tract reconstruction $(n=1)$. No deaths or life-threatening events occurred during the total follow-up period of 18 patient-years. The stenotic segment was significantly enlarged from the preoperative diameter of $0.9 \pm 1.1 \mathrm{~mm}$ (mean \pm standard deviation) to the postoperative diameter of $8.0 \pm 1.3$ $\mathrm{mm}$, values which correspond to $7.0 \% \pm 8.8 \%$ and $68.4 \% \pm 11.5 \%$ of the normative values, respectively. A follow-up angiogram $(n=5)$ revealed an increase in the pulmonary artery diameter balanced with somatic growth (initial value, $65.2 \% \pm 9.0 \%$ of normal; second value, $69.1 \% \pm 7.7 \%$ of normal). No aneurysms or clinically significant restenoses were seen on the angiograms. Conclusions: Our initial midterm results with this method were promising. The pulmonary arteries subjected to this procedure grew in proportion to somatic growth. (J Thorac Cardiovasc Surg 1997;114:406-12)
\end{abstract}

C ongenital and acquired hilar pulmonary artery (PA) stenosis, especially near a previously placed Blalock-Taussig shunt, remains a clinically challenging lesion. Balloon dilatation has been particularly unsuccessful in managing such stenoses. ${ }^{1,2} \mathrm{Al}-$ though the short-term results of intravascular stenting are excellent, stents do not grow in relation to somatic growth and may rather become obstructive. ${ }^{3}$ Consequently, surgical arterioplasty for stenotic lesions is required in some cases. ${ }^{4,5}$ However, the results of patch enlargement of PA stenosis near a previous shunt anastomosis are often unsatisfacto-

From the Department of Thoracic and Cardiovascular Surgery, Kanagawa Children's Medical Center, Yokohama, Japan.

Received for publication Dec. 23, 1996; revisions requested Feb. 3, 1997; revisions received April 14, 1997; accepted for publication April 16, 1997.

Address for reprints: Yukihiro Kaneko, MD, Department of Thoracic and Cardiovascular Surgery, Kanagawa Children's Medical Center, 2-138-4, Mutsukawa Minami-ku, Yokohama 232, Japan.

Copyright (C) 1997 by Mosby-Year Book, Inc.

$0022-5223 / 97 \$ 5.00+0 \quad \mathbf{1 2 / 1 / 8 2 6 6 9}$ ry. ${ }^{6,7}$ Our previous attempts at relieving hilar PA stenosis near a previous Blalock-Taussig shunt through a thoracotomy also resulted in unsatisfactory outcomes. This was not only because intraoperative visibility was hindered by bleeding caused by the dissection of abundant collateral vessels and dense adhesion formed after the previous operation, but also because the use of a prosthetic patch predisposed to later shrinkage and somatic outgrowth. We therefore started to use a new surgical technique called "lay-open" pulmonary arterioplasty (PA-plasty) for the relief of postoperative hilar PA stenosis. In this technique, the surgeon enlarges the stenotic hilar PA by incising and dilating it without dissecting the neighboring scar tissue formed by the previous operation. The extrapericardial segment of the enlarged PA is partly supported by scar tissue, instead of being covered with a prosthetic patch, to avoid restenosis caused by suturing, patch distortion, and somatic outgrowth of the patch. This scar tissue will prevent blood leakage from the PA. However, as the PA loses its vessel integrity, the risks of bleeding, thromboembolism, and aneurysm 


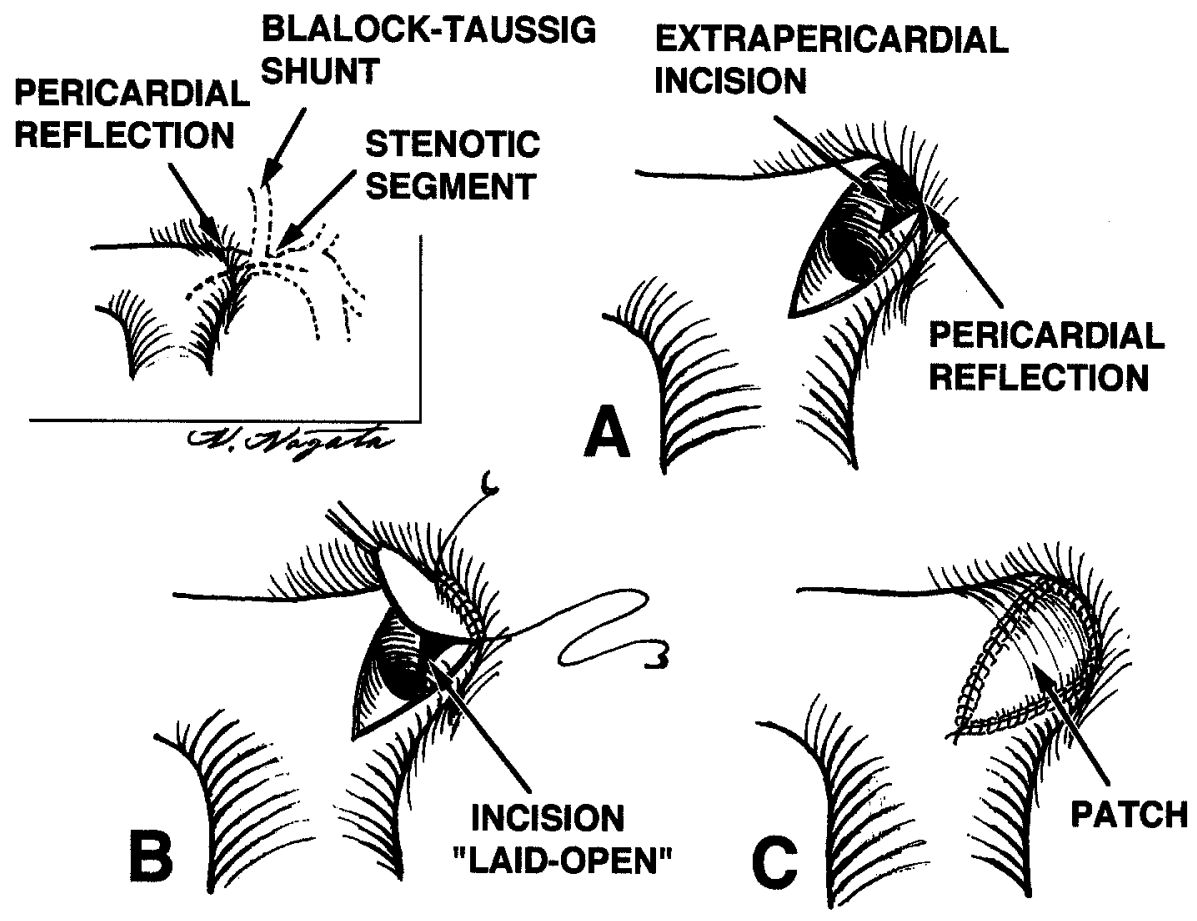

Fig. 1. Surgical technique of the lay-open PA-plasty. A, The PA was incised from the intrapericardial PA to the hilar PA across the stenotic segment. The stenotic segment was then dilated. $\mathbf{B}$, The triangular opening in the intrapericardial PA formed by incisional edges and the pericardial reflection was closed with a patch. The extrapericardial incision was left laid open. C, Final appearance of the PA subjected to the lay-open PA-plasty.

formation increase. This report describes our initial experience with the lay-open PA-plasty.

\section{Methods}

Surgical technique. The lay-open PA-plasty technique is as follows. After cardiopulmonary bypass is established through a median sternotomy, a longitudinal incision is made in the intrapericardial PA and extended distally across the pericardial reflection up to the sufficiently wide PA distal to the hilar stenotic segment. At the extrapericardial portion of the PA, the surgeon sharply incises the vessel wall from inside the vessel cavity with fine scissors, while taking care to preserve the neighboring fibrous scar tissue formed by the previous operation. Because no stitches are to be placed in the hilar PA, the surgeon can incise the vessel wall distally enough to reach the adequately wide PA without considering whether the deepest edge of the incision can be stitched. Subsequently, the surgeon dilates the stenotic segment by the serial insertion of Hegar dilators of increasing sizes or by spreading a Kelly clamp in the vessel. At this time, a triangular opening has been created in the intrapericardial PA. The three sides consist of both edges of the intrapericardial portion of the incision and the pericardial reflection. Meanwhile, although the vessel wall has been incised, there is no true opening in the extrapericardial PA because the extrapericardial portion of the incision is covered with the intact circumferential scar tissue that was not incised. The procedure is finalized by closing the triangular opening in the intrapericardial PA. According to the size of the opening, it is closed directly by transversely suturing the incisional edges to the pericardial reflection by means of the Heineke-Mikulicz method or with a triangular patch. After the procedure, the extrapericardial incision remains "laid-open," that is, a part of the circumference of the incised hilar PA is made up of true PA vessel wall, and the remainder is made up of the intact scar tissue, which prevents blood leakage from the vessel thereafter. The surgical technique is pictured in Fig. 1.

Patient selection. Lay-open PA-plasty was indicated for patients with severe hilar PA stenosis when the stenotic segment seemed barely accessible through a thoracotomy because of dense adhesion formed after the previous operations. The final decision whether to perform PAplasty by the lay-open method or by completely covering the incision with a patch was made during the operation. When the stenotic segment was located proximally enough, the incision was completely patched. We performed the lay-open PA-plasty regardless of pulmonary vascular bed hypoplasia, which could lead to a relatively high PA pressure after the operation.

Patient characteristics. Between April 1989 and July 1996 , a total of 10 patients with cyanotic cardiac anomalies, five boys and five girls, whose ages ranged from 2.2 to 15.7 years (mean 7.6 years), underwent lay-open PAplasty. Anatomic diagnoses included tetralogy of Fallot in 
four patients, tetralogy of Fallot with pulmonary atresia in two patients, and other cyanotic cardiac anomalies in four patients. Nine patients had a previous placement of systemic-PA shunt on the stenotic PA, and the remaining patient had undergone patch enlargement of the stenotic PA via a thoracotomy. Arterioplasty was performed on the left PA in eight patients, including five patients with nonconfluent left PAs, on the right PA in one patient, and on both PAs in one patient with a nonconfluent left PA. The intrapericardial incision was closed with a polytetrafluoroethylene patch* in seven patients, with an equine pericardial patch (model XAG-400, Baxter Edwards AG, Horw, Switzerland) in one patient, and by the HeinekeMikulicz method in two patients. The surgical procedures concomitantly performed in nine patients included total repair in five patients, central interposing shunt in three patients, and palliative right ventricular outflow tract reconstruction in one patient.

Protocol. The medical records during the hospitalization and follow-up periods were reviewed. Chest x-ray films were obtained from all patients every 6 to 12 months after the operation. Chest $\mathrm{x}$-ray films taken immediately after the operation and those taken most recently were examined retrospectively.

Angiography was performed both before and after the operation in every patient and was repeated when necessary. Pressures in the PA proximal and distal to the stenosis, as well as the pressure gradient across the stenosis, were measured during angiography when possible. The mean diastolic values and corresponding systolic values of the following were measured on the angiograms: the minimal diameters of the stenotic segment before and after the operation, the diameter of the descending thoracic aorta just above the level of the diaphragm, the diameter of the contralateral PA immediately proximal to the origin of the first branch, and the diameter of the ipsilateral PA immediately distal to the origin of the first branch. The normative diameters of the right and left PAs immediately proximal to the origin of the first branch against body surface area (BSA) were calculated by the following power functions as described by Sievers and associates. $^{8}$

$$
\begin{aligned}
\text { Right PA diameter }(\mathrm{mm}) & =14.6 \times \operatorname{BSA}\left(\mathrm{m}^{2}\right)^{0.586} \\
\text { Left PA diameter }(\mathrm{mm}) & =13.7 \times \operatorname{BSA}\left(\mathrm{m}^{2}\right)^{0.587}
\end{aligned}
$$

Statistics. Angiographic and catheterization parameters and BSA were expressed as mean \pm standard deviation. The chronologic changes in angiographic parameters and BSA were compared by the paired Student's $t$ test, and $95 \%$ confidence intervals $(95 \% \mathrm{CI})$ were calculated on the assumption that these values followed the $t$ distribution. The relationships among different angiographic parameters were explored by simple linear regression. Statistical significance was set at a $p$ value of less than 0.05 .

\footnotetext{
* Gore-Tex sheet, $0.6 \mathrm{~mm}$, registered trademark of W. L. Gore \& Associates, Inc., Elkton, Md.
}

\section{Results}

Clinical results. All patients were followed up at our hospital, and complete medical records during hospitalization and the follow-up period were obtained. All patients tolerated the procedure without related complications, except for one patient who had left phrenic nerve palsy after the operation. The mortality rate was $0 \%(95 \% \mathrm{CI}, 0 \%$ to $28 \%)$ and the complication rate was $10 \%$ (95\% CI, $2 \%$ to $40 \%$ ). No intrabronchial hemorrhages occurred. The postoperative intensive care unit stay and hospital stay ranged from 1 to 5 days (median 2 days) and 8 to 27 days (median 9.5 days), respectively. The sum total of intraoperative and postoperative blood transfusions ranged from 0 to $1700 \mathrm{ml}$ (median $400 \mathrm{ml}$ ).

The postoperative follow-up periods ranged from 0.5 to 6.6 years (mean 1.8 years). No late deaths occurred during the follow-up period. Among the four patients who had not undergone intracardiac repair at the time of PA-plasty, one patient successfully underwent intracardiac repair 2 months after the PA-plasty, and the remaining three patients are waiting for intracardiac repair. No complaints or physical findings were attributable to intrathoracic bleeding or pulmonary embolism during the follow-up period.

Chest $\mathrm{x}$-ray findings. Chest $\mathrm{x}$-ray films taken immediately after the operation did not reveal any hilar hematoma or massive pleural effusion. The most recent chest $\mathrm{x}$-ray films, taken 0.2 to 6.1 years (mean 1.4 years) after the operation, did not reveal any abnormal shadows suggestive of PA aneurysm or pulmonary embolism.

Short-term angiographic results. Preoperative angiography was performed 1 to 16 months (mean 6 months) before the operation, and postoperative angiography was performed 1 to 4 months (mean 1 month) after the operation. The patients' BSAs increased from $0.75 \pm 0.24 \mathrm{~m}^{2}$ at preoperative angiography to $0.78 \pm 0.23 \mathrm{~m}^{2}$ at postoperative angiography, but the difference was not significant ( $p=0.06 ; 95 \% \mathrm{CI}$ of the difference, $-0.003 \mathrm{~m}^{2}$ to $0.058 \mathrm{~m}^{2}$ ). Eleven PAs treated by lay-open PAplasty in the 10 patients were examined.

The smallest preoperative diameters of the stenotic segments $(0.9 \pm 1.1 \mathrm{~mm} ; 95 \% \mathrm{CI}, 0.1$ to 1.6 $\mathrm{mm}$ ), which corresponded to $7.0 \pm 8.8 \%(95 \% \mathrm{CI}$, $0.8 \%$ to $13.2 \%$ ) of the normative values, were significantly enlarged $(p<0.001 ; 95 \% \mathrm{CI}$ of the difference, 6.1 to $8.2 \mathrm{~mm}$ ) to postoperative values $(8.0 \pm 1.3 \mathrm{~mm}$; $95 \% \mathrm{CI}, 7.1$ to $8.9 \mathrm{~mm})$ corresponding to $68.4 \% \pm 11.5 \%$ (95\% CI, $60.3 \%$ to $76.5 \%$ ) of 


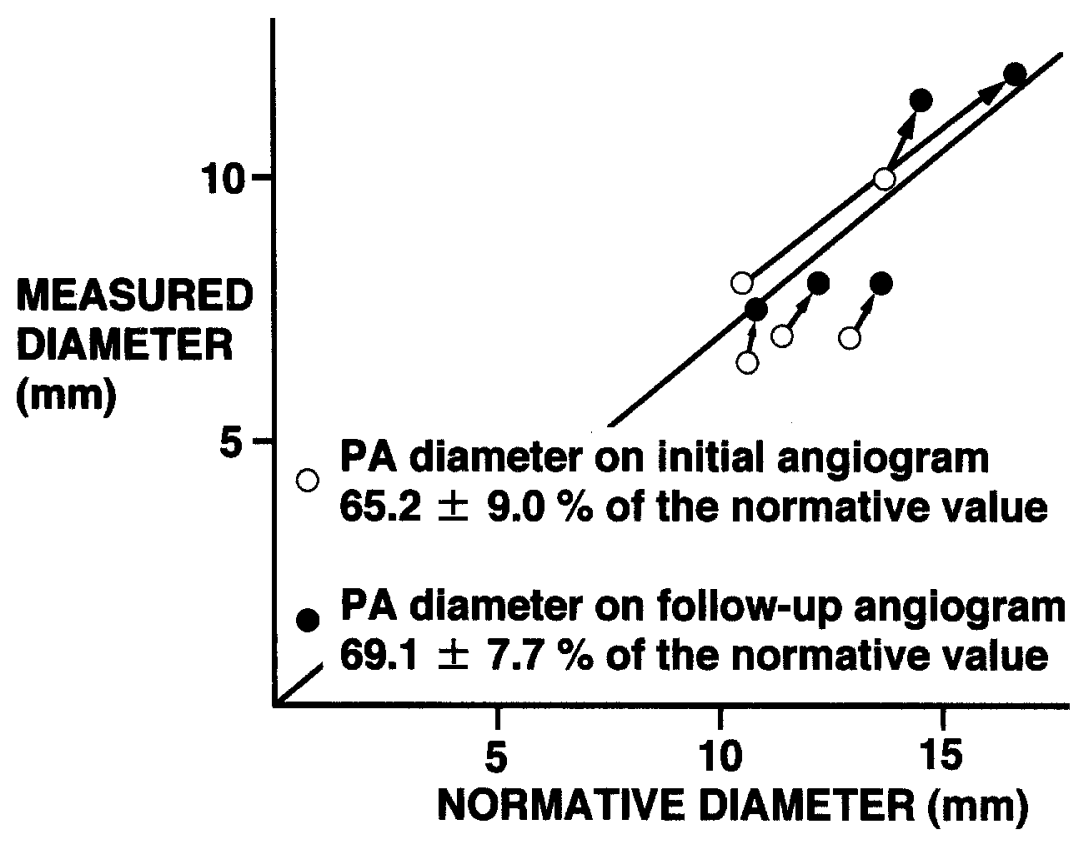

Fig. 2. The postoperative PA diameters on initial and follow-up angiograms versus normative hilar PA diameter are depicted. Arrows indicate growth of the PAs. The oblique line shows $70 \%$ of the normative PA diameter.

the normative values. The smallest postoperative diameter of the enlarged segment (Y) correlated with the preoperative diameter of the ipsilateral PA distal to the first branch $(\mathrm{X})$ by a simple linear regression. The linear regression equation was as follows:

$$
\mathrm{Y}(\mathrm{mm})=0.51 \mathrm{X}+3.1(\mathrm{~mm})
$$

(correlation coefficient: $r=0.63, p=0.04$ ). The minimal postoperative diameter of the enlarged segment did not correlate with the other angiographic values, including the preoperative diameter of the corresponding segment and the preoperative and postoperative contralateral PA diameters, aortic diameters, and the normative PA diameters.

The postoperative PA pressure proximal to the enlarged segment $(n=9)$ was $44 \pm 13 \mathrm{~mm} \mathrm{Hg}$ (range 21 to $60 \mathrm{~mm} \mathrm{Hg}$ ), corresponding to $45 \% \pm$ $14 \%$ of the systemic arterial pressure (range 19\% to $62 \%$ ). The postoperative pressure gradient across the stenotic segments $(n=8)$ was $17 \pm 10 \mathrm{~mm} \mathrm{Hg}$ (range 0 to $32 \mathrm{~mm} \mathrm{Hg}$ ).

Long-term angiographic results. Five patients underwent a follow-up angiogram 0.7 to 5.8 years (mean 1.9 years) after the initial postoperative angiogram. These patients' BSAs increased from $0.78 \pm 0.16 \mathrm{~m}^{2}$ at the initial angiogram to $0.99 \pm$
$0.27 \mathrm{~m}^{2}$ at the follow-up angiogram, but the difference was not significant $(p=0.19 ; 95 \% \mathrm{CI}$ of the difference, $-0.20 \mathrm{~m}^{2}$ to $0.62 \mathrm{~m}^{2}$ ). The smallest postoperative diameter of the enlarged segment increased significantly from $7.7 \pm 1.4 \mathrm{~mm}$ on the initial postoperative angiogram to $9.4 \pm 2.2 \mathrm{~mm}$ on the follow-up angiogram $(p=0.04 ; 95 \% \mathrm{CI}$ of the difference, $0.0 \mathrm{~mm}$ to $3.4 \mathrm{~mm}$ ). In Fig. 2, the growth of the smallest diameter of the enlarged segment in each patient was plotted against the growth of the normative hilar PA diameter in the same patient.

In the total of 16 postoperative angiograms of 11 enlarged PAs, no aneurysm formation, restenosis, or PA thrombosis was seen.

\section{Discussion}

Study limitations. Several limitations are inherent to this study. Indications for use of the technique were arbitrary and the criteria unclear. The follow-up period and the period between the initial and follow-up postoperative angiograms may be too short. A follow-up angiogram was obtained in only a small percentage of the cohort, possibly introducing bias into the study.

Technical feasibility. The maneuvers of the layopen PA-plasty are technically easy. While incising the vessel wall, we were not certain of the depth of 

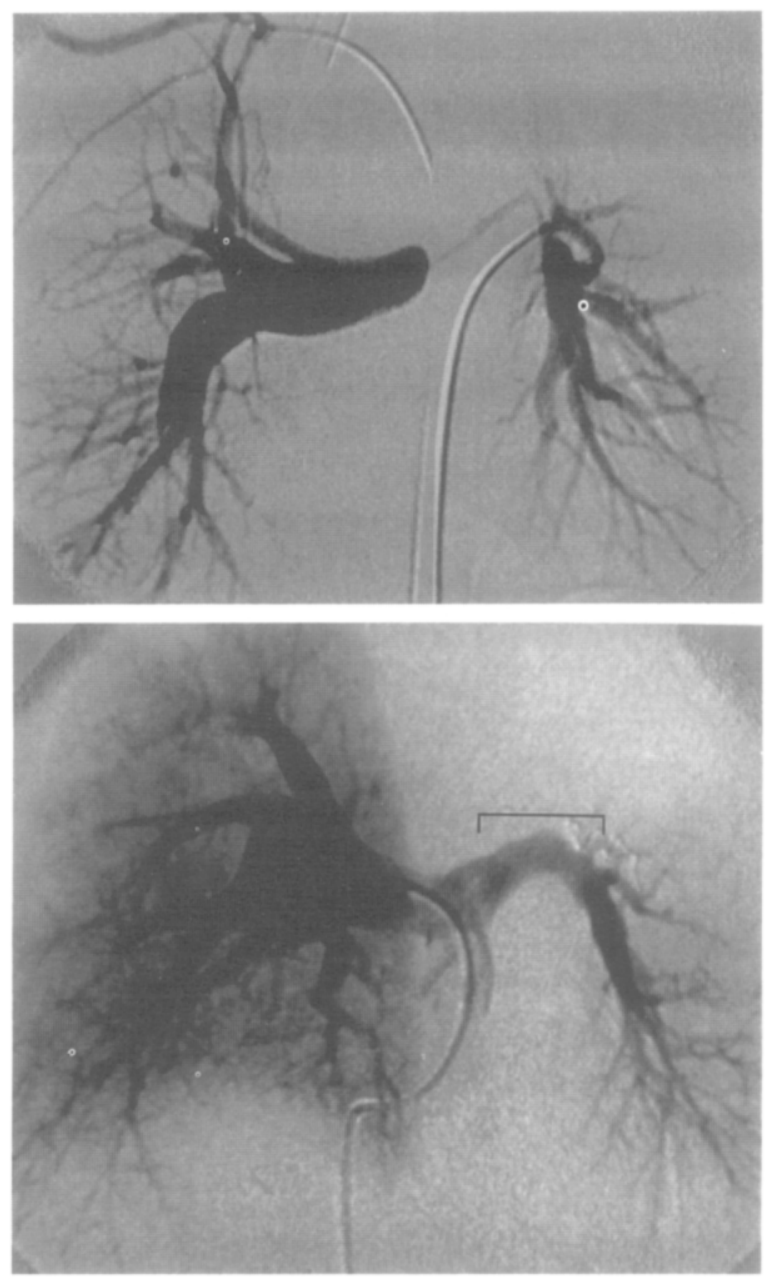

Fig. 3. Representative preoperative (upper) and postoperative (lower) pulmonary arteriograms in a patient with tetralogy of Fallot, pulmonary atresia, and nonconfluent PA. Intracardiac repair was performed concomitantly. Note that the surgically enlarged segment, indicated by a bracket, smoothly merged with the slender distal PA that perfused the hypoplastic pulmonary vascular bed.

the incision into the adventitia, because the adventitia merges imperceptibly with the fibrous tissue surrounding it. The fibrous tissue seemed firm enough to prevent blood leakage in all cases. The surgeon comfortably incised the vessel wall en bloc. Because the area of suturing was limited to within the pericardial cavity, the incision was closed without difficulty. In our experience with these 10 patients, we found lay-open PA-plasty to be technically simple.

Safety and efficacy. Danielson and associates ${ }^{9}$ showed that the fibrous scar tissue that developed over the prosthetic conduit was secure enough to support vessel integrity in the pulmonary circulation. If the lay-open PA-plasty were applied to patients who had not had a previous operation, the safety of this procedure would be questionable. In this preliminary study, all patients had previously undergone surgery on the stenotic PA, and no bleeding, aneurysmal, or thromboembolic complications occurred after the lay-open PA-plasty. The only surgical complication in our series, left phrenic nerve palsy, could be attributable to the ice slush that we routinely place over the heart during cardiac arrest or to the dissection and occlusion of a previously placed left modified Blalock-Taussig shunt. These findings imply a certain degree of safety with this procedure in patients who have had a previous operation, although longer follow-up is necessary.

In our previous PA-plasty experiences in which the PA incision across the pericardial reflection was completely covered with a patch, residual and recurrent stenosis often occurred at the pericardial reflection (especially on the left side) and at the toe of the patch. Free autologous pericardial patches often shrank later and thereby induced restenosis. Because the left PA spirals around the left bronchus, the patches tended to go awry at the pericardial reflection. This probably predisposed to postoperative stenosis at the pericardial reflection. The stenosis at the toe of the patch is attributable to the suturing of the patch itself. Stenosis in both areas can probably be prevented by the lay-open method.

Fogelman and associates ${ }^{3}$ reported a diameter increase of $109 \% \pm 79 \%$ in the stenotic branch PA after implanting an endovascular stent. Hosking and associates ${ }^{10}$ reported that the mean increases in the right and left PA diameters by balloon angioplasty were $56 \%$ and $17 \%$, respectively. The increase in the PA diameter produced by the lay-open PA-plasty was greater than these results.

The postoperative PA diameter did not reach the normative value. This was probably because the PA distal to the stenosis was diminutive and the vascular bed perfused by the PA was hypoplastic (Fig. 3).

Growth potential. Although the short-term results of intravascular stenting are encouraging, restenosis may occur as a result of tissue ingrowth and somatic outgrowth. Fogelman and associates ${ }^{3}$ reported that recatheterization $10 \pm 4$ months after stent implantation revealed a $20 \% \pm 21 \%$ decrease in the luminal diameter.

As shown in Fig. 2, the diameter of the stenotic PA after the lay-open PA-plasty increased in proportion to the increase in BSA. This result indicates 
the growth potential of the PA after the operation. The youngest patient undergoing follow-up angiography was 3.7 years of age at the time of the initial postoperative angiogram. PA growth balanced with somatic growth after this procedure has not been confirmed in younger patients, who grow faster.

Direct end-to-end anastomosis combined with resection of the stenotic segment is an alternative PA-plasty method with growth potential. ${ }^{11}$ However, inasmuch as extensive mobilization of the PA is necessary to approximate both ends of the vessel, direct anastomosis is applicable in the initial procedure, but is not practical in patients with several previous surgical procedures. Another alternative method with growth potential is the use of a pedicled autologous pericardial flap as a patch. ${ }^{12,13} \mathrm{We}$ regard pedicled pericardial patch enlargement as attractive, yet the lay-open method seems technically easier.

The present study provides initial data on the lay-open PA-plasty method. A longer follow-up of the patients until adulthood and a larger cohort are necessary to establish the efficacy and safety of this technique. However, the preliminary results presented herein are promising.

\section{REFERENCES}

1. Rocchini AP, Kveselis D, Dick M, Crowley D, Snider AR, Rosenthal A. Use of balloon angioplasty to treat peripheral pulmonary stenosis. Am J Cardiol 1984;54:1069-73.

2. Ring JC, Bass JL, Marvin W, Fuhrman BP, Kulik TJ, Foker JE, et al. Management of congenital stenosis of branch pulmonary artery with balloon dilation angioplasty. $\mathbf{J}$ Thorac Cardiovasc Surg 1985;90:35-44.

3. Fogelman R, Nykanen D, Smallhorn JF, McCrindle BW, Freedom RM, Benson LN. Endovascular stents in the pulmonary circulation: clinical impact on management and medium-term follow-up. Circulation 1995;92:881-5.

4. Yamaguchi M, Tachibana H, Hosokawa Y Ohashi H, Imai M. Staged repair of supravalvular aortic stenosis associated with severe multiple peripheral stenoses: report of extended peripheral pulmonary arterioplasty. J Thorac Cardiovasc Surg 1987;93:785-93.

5. Fraser CD Jr, Latson LA, Mee RBB. Surgical repair of severe bilateral branch pulmonary artery stenosis. Ann Thorac Surg 1995;59:738-40.

6. Cooley DA, Smith JM. Repair of pulmonary arterial stenosis after Waterston-Cooley anastomosis. J Thorac Cardiovasc Surg 1979;77:474-7.

7. Wilson JM, Mack JW, Turley K, Ebert PA. Persistent stenosis and deformity of the right pulmonary artery after correction of the Waterston anastomosis. J Thorac Cardiovasc Surg 1981;82:169-75.

8. Sievers HH, Onnasch DG, Lange PE, Bernhard A, Heinzen $\mathrm{PH}$. Dimensions of the great arteries, semilunar valve roots, and right ventricular outflow during growth: normative angiographic data. Pediatr Cardiol 1983;4:189-96.
9. Danielson GK, Downing TP, Schaff HV, Puga FJ, Di Donato M, Ritter DG. Replacement of obstructed extracardiac conduits with autogenous tissue reconstructions. J Thorac Cardiovasc Surg 1987;93:555-9.

10. Hosking MCK, Thomaidis $C$, Hamilton R, Burrows PE, Freedom RM, Benson LN. Clinical impact of balloon angioplasty for branch pulmonary arterial stenosis. Am J Cardiol 1992;69:1467-70.

11. Hennein HA, Mosca RS, Urcelay G, Crowley DC, Bove EL. Intermediate results after complete repair of tetralogy of Fallot in neonates. J Thorac Cardiovasc Surg 1995;109:332-44.

12. Guyton RA, Dorsey LM, Silberman MS, Hawkins HK, Williams WH, Hatcher CR Jr. The broadly based pericardial flap: a tissue for atrial wall replacement that grows. $\mathbf{J}$ Thorac Cardiovasc Surg 1984;87:619-25.

13. Khoury W, Lang-Lazdunski L, Vernant F, Thibert M, Leca F. Pedicled pericardium for repair of right ventricular outflow tract and pulmonary arterial stenoses in tetralogy of Fallot: a six-year experience. J Thorac Cardiovasc Surg 1996;112:424-32.

\section{Commentary}

In this issue of the Journal, Kaneko and his colleagues report on their experience with a new method of surgically managing acquired pre-hilar and hilar branch pulmonary artery (PA) stenosis. The method, which they term "layopen" pulmonary arterioplasty, entails longitudinally opening the intrapericardial portion of the affected PA up to the pericardial reflection. The surgeon then works more distally from within the opened PA lumen to sharply incise longitudinally only the true PA wall to a point beyond the distal end of the stenosis. By working from within the lumen, the surgeon leaves the scar tissue surrounding the PA intact. The new distal lumen, partly made up of true PA and partly made up of scar tissue, is then actively dilated with probes. No attempt is made to patch the extrapericardial portion of the incised and dilated PA. The integrity of the new "vessel" relies on the encasing scar tissue and the adherence of the incised edge of the true PA wall to that scar.

This procedure, if proven safe and durable, would have its most appropriate application to cases of iatrogenic stenoses at the site of previously created systemic-PA shunts placed extrapericardially via a thoracotomy.

Distal PA reconstruction represents one of the most demanding technical procedures facing the surgeon who deals with congenital heart disease. New techniques that improve our ability to handle such problems will be enthusiastically accepted by all who deal with such problems. A note of caution, however, must be struck before the pediatric cardiac surgical community embraces the technique described in this article. Although the method appears promising (it has a certain degree of similarity with balloon angioplasty, i.e., disruption of the vessel wall to achieve increased diameter), the authors provide only limited follow-up on a very small patient cohort. The authors have shown that the diameter of the vessel at the site of their reconstruction seems to enlarge significantly over time. Of concern is the mechanism of this increase in diameter. Does the procedure allow the previously stenotic PA to begin to grow in a relatively normal fashion, or is the increase in diameter the result of dilation caused by 


\section{Kaneko et al.}

stresses on tissues that are not designed to be vascular conduits, that is, scar tissue. If the latter mechanism is operative, such stresses could result in unchecked dilation and aneurysm formation. The authors report on a mean follow-up time of 1.9 years in five patients. This is certainly not sufficient time to rule out the development of PA aneurysms at the site of reconstruction.
The Journal of Thoracic and Cardiovascular Surgery September 1997

The authors should be acknowledged for developing and applying a potentially useful new method of managing a difficult surgical problem. I await with interest further follow-up reports on this interesting patient population.

Frank L. Hanley, $M D$

San Francisco, Calif.

12/1/83795

\section{ON THE MOVE?}

Send us your new address at least six weeks ahead

Don't miss a single issue of the journal! To ensure prompt service when you change your address, please photocopy and complete the form below.

Please send your change of address notification at least six weeks before your move to ensure continued service. We regret we cannot guarantee replacement of issues missed due to late notification.

\section{JOURNAL TITLE:}

Fill in the title of the journal here.

\section{OLD ADDRESS:}

Affix the address label from a recent issue of the journal here.

\section{NEW ADDRESS:}

Clearly print your new address here.

Name

Address

City/State/ZIP
COPY AND MAIL THIS FORM TO: Journal Subscription Services Mosby-Year Book, Inc. 11830 Westline Industrial Dr. St. Louis, MO 63146-3318
OR FAX TO:

314-432-1158

NM Mosby
OR PHONE:

1-800-453-4351

Outside the U.S., call 314-453-4351 